\title{
Increased expression of angiogenic growth factors in age-related maculopathy
}

\author{
Mike Kliffen, Hari S Sharma, Cornelia M Mooy, Sonja Kerkvliet, Paulus T V M de Jong
}

Institute of

Ophthalmology,

Erasmus University,

Rotterdam, the

Netherlands

M Kliffen

C M Mooy

Institute of

Pharmacology,

Erasmus University,

Rotterdam, the

Netherlands

H S Sharma

Institute of Pathology,

Erasmus University,

Rotterdam, the

Netherlands

C M Mooy

S Kerkvliet

Netherlands

Ophthalmic Research

Institute, Amsterdam,

the Netherlands

P T V M de Jong

Correspondence to:

Dr M Kliffen, Department of

Ophthalmic-Pathology,

Hoboken Ee 993, Erasmus

University, PO Box 1738 ,

3000 DR Rotterdam, the

Netherlands.

Accepted for publication 4 October 1996

\begin{abstract}
Aims/background-The late stages of agerelated maculopathy (ARM), especially neovascular macular degeneration (ARMD), can severely affect central vision and are the main cause of blindness in the elderly in the Western world. It has been shown that angiogenic growth factors are present in neovascular membranes in ARMD. However, it is not known if angiogenic growth factors play a role in the onset of neovascularisation.

Methods-In order to elucidate the involvement of angiogenic growth factors in the initiation of neovascularisation in early stages of ARM, the expression patterns of VEGF, TGF- $\beta$, b-FGF, and PDGF-AA on 18 human maculae with ARM, and on 11 control specimens were investigated immunohistochemically.

Results-A significantly increased expression of VEGF $(p=0.00001)$ and TGF- $\beta$ $(p=0.019)$ was found in the retinal pigment epithelium (RPE) of maculae with ARM compared with control maculae. Furthermore, an increased expression of VEGF and PDGF was found in the outer nuclear layer of maculae with ARM.

Conclusion-These results demonstrate an increased expression of VEGF in the RPE, and in the outer nuclear layer in maculae with ARM, that could be involved in the pathogenesis of neovascular macular degeneration. Furthermore, enhanced TGF- $\beta$ expression in the RPE cells of maculae with early stages of ARM was shown.
\end{abstract}

(Br f Ophthalmol 1997;81:154-162)

Age-related maculopathy (ARM) is a disorder of the macular area of the eye. Many histopathological changes-for example, drusen and basal laminar deposit (BLD) can be seen in early types of ARM. ${ }^{12}$ The late stages of ARM are nowadays called age-related macular degeneration (ARMD) and are subdivided into dry ARMD (geographic atrophy), and wet ARMD (neovascular ARMD). ${ }^{3}$ ARMD is the main cause of blindness in the elderly population in the Western world. In the Netherlands the prevalence of neovascular ARMD is twice as high as dry ARMD, ${ }^{4}$ whereas there is an equal distribution between the two in the USA. ${ }^{5}$ During neovascular ARMD, the subretinal pigment epithelial (RPE) space is invaded by growing new blood vessels (angiogenesis) sprouting from the underlying choriocapillaris. ${ }^{1267}$ These neovas- cular blood vessels can cause haemorrhages, leading to the formation of a disciform scar with rapid visual impairment. Despite several studies on the morphology of ARM, the molecular mechanisms and factors contributing to the pathogenesis of neovascular ARMD remain to be characterised.

Angiogenesis, being a complex phenomenon comprising several distinct processes that include endothelial cell migration and proliferation, extracellular proteolysis, and vessel wall remodelling, has been implicated in many pathophysiological processes. Several growth factors have been shown to contribute to the molecular events involved in the regulation of blood vessel growth. ${ }^{89}$ Likewise, it is assumed that angiogenic growth factors such as vascular endothelial growth factor (VEGF), transforming growth factor $\beta$ (TGF- $\beta$ ), basic fibroblast growth factor (b-FGF), and platelet derived growth factor (PDGF) could play an important role in the pathogenesis of neovascular ARMD.

VEGF, also referred to as vascular permeability factor or vasculotrophin, is a heparin binding peptide mitogen with narrow target cell specificity, apparently limited to endothelial cells derived from small and large blood vessels. It promotes vascular permeability and angiogenesis in vivo. ${ }^{9}$ TGF- $\beta$ is a cytokine that has been implicated in cell proliferation, angiogenesis, and deposition of extracellular matrix. ${ }^{10}$ Another angiogenic heparin binding growth factor, b-FGF, has been suggested to contribute to the process of ocular neovascularisation. ${ }^{11-13}$ PDGF is highly chemotactic to the RPE cells, ${ }^{14}$ and is known to induce intraocular vascular proliferation. ${ }^{15}$ Cultured RPE cells have been shown to produce all the above mentioned growth factors. ${ }^{16-20}$

Recently, increased levels of VEGF, b-FGF, and TGF- $\beta$ in surgically removed neovascular membranes from eyes with neovascular ARMD have been demonstrated. ${ }^{11221}$ However, it is not yet established whether these growth factors play a role in the initiation of the process or they are secondary to the new blood vessel formation. The purpose of this study was to investigate the possible presence of angiogenic growth factors (VEGF, TGF- $\beta$, b-FGF, and PDGF-AA) in the early stages of ARM - that is, before the onset of neovascularisation.

Materials and methods

PREPARATION OF HUMAN MACULAR TISSUE

We used 29 human eye bank eyes from 25 subjects aged between 38 and 96 years (mean age 
78 years), with postmortem time from 1 to 11 hours (mean 7 hours). The donors had no history of eye disease, and the samples were macroscopically and microscopically checked for retinal diseases that might stimulate angiogenesis - for example, diabetic retinopathy. The macular area (about $1 \mathrm{~cm}^{2}$ ) was dissected from the ocular tissue, fixed in phosphate buffered formaldehyde $(4 \% \mathrm{v} / \mathrm{v}, \mathrm{pH} 7.4)$, and embedded in paraffin for histopathological classification and immunohistochemistry.

HISTOPATHOLOGICAL CLASSIFICATION OF HUMAN MACULAR TISSUE

Serial paraffin sections $(5 \mu \mathrm{m})$ of half the maculae were made. At regular intervals (three depths) these were stained with haematoxylin and eosin, the periodic acid Schiff reaction, and Mallory staining. The maculae were histologically classified according to their gradation of drusen and BLD. Drusen and BLD are both extracellular deposits accumulating in ARM. Drusen are located external to the basement membrane of the RPE-that is, within Bruch's membrane. BLD is located between the basal cell membrane and the basement membrane of the RPE - that is, outside Bruch's membrane. Large drusen and BLD (and the chemical composition of these deposits) are assumed to be important determinants in the pathogenesis of ARM. ${ }^{22-27}$ (For the classification of drusen and BLD see van der Schaft et al. ${ }^{28}$ ) In brief the classification is: no BLD (class 0); small solitary patches of BLD (class 1); a thin continuous layer of BLD (class 2); a thick layer of BLD of at least half the height of the RPE cells (class 3); no drusen (class 0 ); 1 to 3 drusen (class 1); 4 to 10 drusen (class 2); many or confluent drusen (class 3$){ }^{28}$

Since no important changes in histology of the maculae are present in maculae with both BLD class 0 or class 1 and drusen class 0 or class 1 , these eyes were categorised as control samples. All other maculae were classified as samples with ARM. Two maculae with established neovascular ARMD were also included for examination of growth factor expression.

IMMUNOHISTOCHEMISTRY

Paraffin sections $(5 \mu \mathrm{m})$ of all maculae were mounted on 3-amino-propyl-trioxysilane (Sigma, St Louis, MO, USA) coated glass slides. After deparaffinisation and rehydration they were rinsed with water and phosphate buffered saline. The slides were placed in a Sequenza Immunostaining Workstation (Shandon Scientific Ltd, Astmoor, Runcorn), and incubated for 20 minutes with normal goat serum. After this blocking step, slides were incubated for 30 minutes with either a rabbit polyclonal antibody directed against VEGF (Santa Cruz Biotechnology, Santa Cruz, CA, USA), ${ }^{29}$ TGF- $\beta$ (R\&D Systems Europe, Abingdon), ${ }^{11}$, b-FGF (Serotec, Kidlington, Oxford), ${ }^{30}$ or PDGF-AA (Genzyme, Cambridge, MA, USA). ${ }^{31}$ These antibodies were characterised as described by the suppliers and in the literature and were used at a dilution of $1: 100,1: 1500,1: 400$, and $1: 150$, respectively. The anti-TGF- $\beta$ polyclonal antibody was panspecific to the several subtypes of TGF- $\beta$. After washing with phosphate buffered saline, the slides were incubated for 30 minutes with biotinylated secondary antibodies (Multilink, 1:75 dilution, Biogenex, San Ramon, MO, USA). The slides were washed again and incubated for 30 minutes with alkaline phosphatase conjugated streptavidin (Biogenex, San Ramon, MO, USA, dilution 1:50). Finally, the slides were rinsed with $0.2 \mathrm{M}$ TRIS- $\mathrm{HCl} \mathrm{pH}$ 8.0, and stained for 30 minutes with $0.3 \% \mathrm{New}$ Fuchsin/TRIS-HCl (Sigma, St Louis, MO, USA). The sections were counterstained with Mayer's haematoxylin for 15 seconds, rinsed for 10 minutes with water, and air dried. Before the incubation with anti-TGF- $\beta$ and anti-bFGF antibodies, the sections were treated with $5 \mu \mathrm{g} / \mathrm{ml}$ saponin for 30 minutes at room temperature, and with $5.5 \mathrm{mU} / \mathrm{ml}$ pronase $\mathrm{E}$ (Sigma, St Louis, MO, USA) for 7 minutes at $37^{\circ} \mathrm{C}$, respectively.

In negative controls, the primary antibodies were replaced by normal rabbit serum (Dako, Glostrup, Denmark, dilution 1:10). As a second negative control for VEGF immunostaining, the anti-VEGF antibodies were blocked with the VEGF peptide (Santa Cruz Biotechnology) before the incubation of the tissue. We did not perform peptide blocking with the other antibodies, because the most important findings in this study concern VEGF. Furthermore, the anti-TGF- $\beta$ antibody is panspecific and the two other antibodies have been described in the literature. ${ }^{113031}$ Blood vessels were used as internal positive controls for anti-VEGF and anti-PDGF antibodies. Nerve fibres were used as internal positive controls for TGF- $\beta$ and b-FGF immunostaining. Growth factor expression was semiquantified on the basis of percentage of positively stained tissue, and to a lesser extent the intensity of tissue staining: $-=$ no staining; $+/-=$ faint staining in less than $50 \%$ of the tissue; $+=$ positive staining in less than $50 \%$ of the tissue; $++=$ positive staining in more than $50 \%$ of the tissue. Sections were scored twice (by the first and third author) with a 3 week interval. Intraobserver variability was negligible. Interobserver variability was only observed between $+/-$ and + scores in some cases. These cases were scored after mutual consultation. In our opinion, these four gradation groups are readily discriminated, especially because positive staining occurred either in less than $33 \%$ of the tissue or in more than $66 \%$ of the tissue. We have chosen to leave out the $33 \%$ to $66 \%$ group in our gradation system for simplification since none of the specimens had a positive staining percentage between $33 \%$ and $66 \%$.

STATISTICAL ANALYSIS

To compare the protein expression of VEGF, TGF- $\beta$, b-FGF, and PDGF between ARM maculae and controls, we have used the Mann-Whitney U test, because this is one of the few non-parametric statistics that has a useful interpretation. The difference of the individual growth factor expression between ARM and control maculae was assumed to be statistically significant if $p<0.05$. Because 
Table 1 Classification of human maculae

\begin{tabular}{|c|c|c|c|c|c|}
\hline Case no & Age & $P M$ & $\begin{array}{l}\text { BLD } \\
\text { class }\end{array}$ & $\begin{array}{l}\text { Drusen } \\
\text { class }\end{array}$ & $\begin{array}{l}\text { Classification of } \\
\text { macula }\end{array}$ \\
\hline 1 & 64 & 10 & 0 & 3 & ARM \\
\hline 2 & 86 & 10 & 2 & 0 & ARM \\
\hline 3 & 88 & 8 & 2 & 0 & ARM \\
\hline 4 & 67 & 8 & 2 & 0 & ARM \\
\hline 5 & 85 & 4.5 & 2 & 1 & ARM \\
\hline 6 & 67 & 11 & 2 & 1 & ARM \\
\hline 7 & 81 & 7 & 2 & 2 & ARM \\
\hline 8 & 87 & 5 & 2 & 2 & ARM \\
\hline 9 & 65 & 8 & 2 & 3 & ARM \\
\hline 10 & 94 & 10 & 3 & 0 & ARM \\
\hline 11 & 74 & 8 & 3 & 0 & ARM \\
\hline 12 & 74 & 8 & 3 & 0 & ARM \\
\hline 13 & 81 & 7 & 3 & 1 & ARM \\
\hline 14 & 86 & 5 & 3 & 2 & ARM \\
\hline 15 & 96 & 2 & 3 & 3 & ARM \\
\hline 16 & 93 & 4.5 & 3 & 3 & ARM \\
\hline 17 & 91 & 8 & 3 & 2 & $\mathrm{ARM} \dagger$ \\
\hline 18 & 87 & 11 & 3 & 3 & $\mathrm{ARM} \dagger$ \\
\hline 19 & 76 & 7 & 0 & 0 & Control \\
\hline 20 & 55 & 7 & 0 & 0 & Control \\
\hline 21 & 38 & 9.5 & 0 & 0 & Control \\
\hline 22 & 91 & 4.5 & 0 & 0 & Control \\
\hline 23 & 81 & 5.5 & 0 & 0 & Control \\
\hline 24 & 80 & 9.5 & 0 & 0 & Control \\
\hline 25 & 45 & 8.5 & 0 & 0 & Control \\
\hline 26 & 77 & 9 & 0 & 0 & Control \\
\hline 27 & 77 & 9 & 0 & 0 & Control \\
\hline 28 & 87 & 1 & 0 & 1 & Control \\
\hline 29 & 91 & 8 & 1 & 1 & Control \\
\hline
\end{tabular}

PM = postmortem time in hours; $\mathrm{BLD}=$ basal laminar deposit; ARM = age-related maculopathy; ${ }^{\star}$ Classification based on the gradation of BLD and drusen (see materials and methods); †Neovascular ARMD.

photoreceptors and inner retinae were not present in 12 specimens (a common problem with postmortem human eyes), $p$ values could not be computed for these tissue layers.

\section{Results}

HISTOPATHOLOGICAL CLASSIFICATION OF HUMAN MACULAR TISSUE

Eleven maculae were classified as controls, nine maculae had neither BLD nor drusen, one macula had BLD class 1 , and one macula had BLD class 1 and drusen class 1 (Table 1). Sixteen specimens were classified as maculae with ARM; six maculae had only BLD (class 2 or 3), 1 macula had only drusen (class 3 ), and nine maculae had both BLD (class 2 or 3 ) and drusen (class 2 or 3) (Table 1). Two maculae had neovascular ARMD (Table 1). The difference of mean age between controls (73 years) and ARM eyes (81 years) was not statistically significant (Student's $t$ test, $\mathrm{p}>0.1$ ).

IMMUNOLOCALISATION OF VEGF

Immunohistochemically, VEGF was localised in the smooth muscle cells of the blood vessels of the choroid and in some of the RPE cells in control maculae (Fig 1A). A significant increase in VEGF expression was found in the RPE cells $(p=0.00001)$ and choroidal blood vessels $(p=0.0064)$ of human maculae with early ARM and maculae with neovascular ARMD compared with controls (Fig 1B). Furthermore, the outer nuclear layer of human maculae with ARM and neovascular ARMD showed more VEGF immunoreactivity (Fig 1C) than those of control maculae. VEGF expression was also found in BLD (nine out of 17 maculae) (Fig 1C). Except for one large calcified drusen that showed positive staining for VEGF (Fig 1D), none of the drusen stained. Additionally, strong positive staining for VEGF was found in macrophages infiltrating through Bruch's membrane (Fig 1E). In negative controls, no staining was seen at all.

IMMUNOLOCALISATION OF TGF- $\beta$

TGF- $\beta$ was scarcely localised in some of the RPE cells, and in the walls of blood vessels (smooth muscle cells as well as endothelial cells) in the choroid of control human maculae (Fig 2A). A significantly increased expression of TGF- $\beta$ was found in the RPE of human maculae with early ARM, and in maculae with neovascular ARMD compared with control specimens $(p=0.019)$. The expression in the choroid was the same in both groups. BLD stained with antibodies directed against TGF- $\beta$ in eight out of 17 maculae (Fig 2B). These were the same maculae that showed expression of VEGF in BLD. None of the drusen stained with the anti-TGF- $\beta$ antibody (Fig 2B).

\section{IMMUNOLOCALISATION OF B-FGF}

Antibodies directed against b-FGF showed expression of this growth factor in all RPE cells and in the blood vessels of the choroid in control human maculae. A significantly decreased expression of b-FGF was found in the choroidal blood vessels of ARM maculae ( $p=$ $0.0005)$, but no difference in expression was found in the RPE or in the photoreceptors. The distribution of b-FGF in ARM maculae is reflected in Figure 2C. BLD stained weakly with anti-b-FGF antibodies in nine out of 17 maculae; seven of these also stained with antiVEGF and anti-TGF- $\beta$ antibodies. The extracellular matrix surrounding the macrophages infiltrating through Bruch's membrane also stained weakly positive for b-FGF. None of the drusen stained with the anti-b-FGF antibody.

\section{IMMUNOLOCALISATION OF PDGF-AA}

In control maculae PDGF was only localised in the smooth muscle cells of the blood vessels. The outer nuclear layer in three maculae with early stages of ARM, and both maculae with neovascular ARMD stained strongly, whereas the inner nuclear layer, and ganglion cell layer stained positive as well (Fig 2D). None of the control specimens showed positive staining in the retinal layers. Some RPE cells stained weakly in six maculae with ARM and in four controls. BLD did not express PDGF. One large drusen involved in the edge of a neovascular membrane showed positive staining for PDGF-AA (Fig 2E). All other drusen were negative.

The differences of growth factor expression, in the RPE and choroid, between ARM maculae and controls are visualised in Figure 3. The statistical analysis was performed on these data.

\section{Discussion}

We have demonstrated a significantly increased expression of VEGF and TGF- $\beta$ in RPE cells of human maculae with early stages of ARM compared with those of control specimens. 

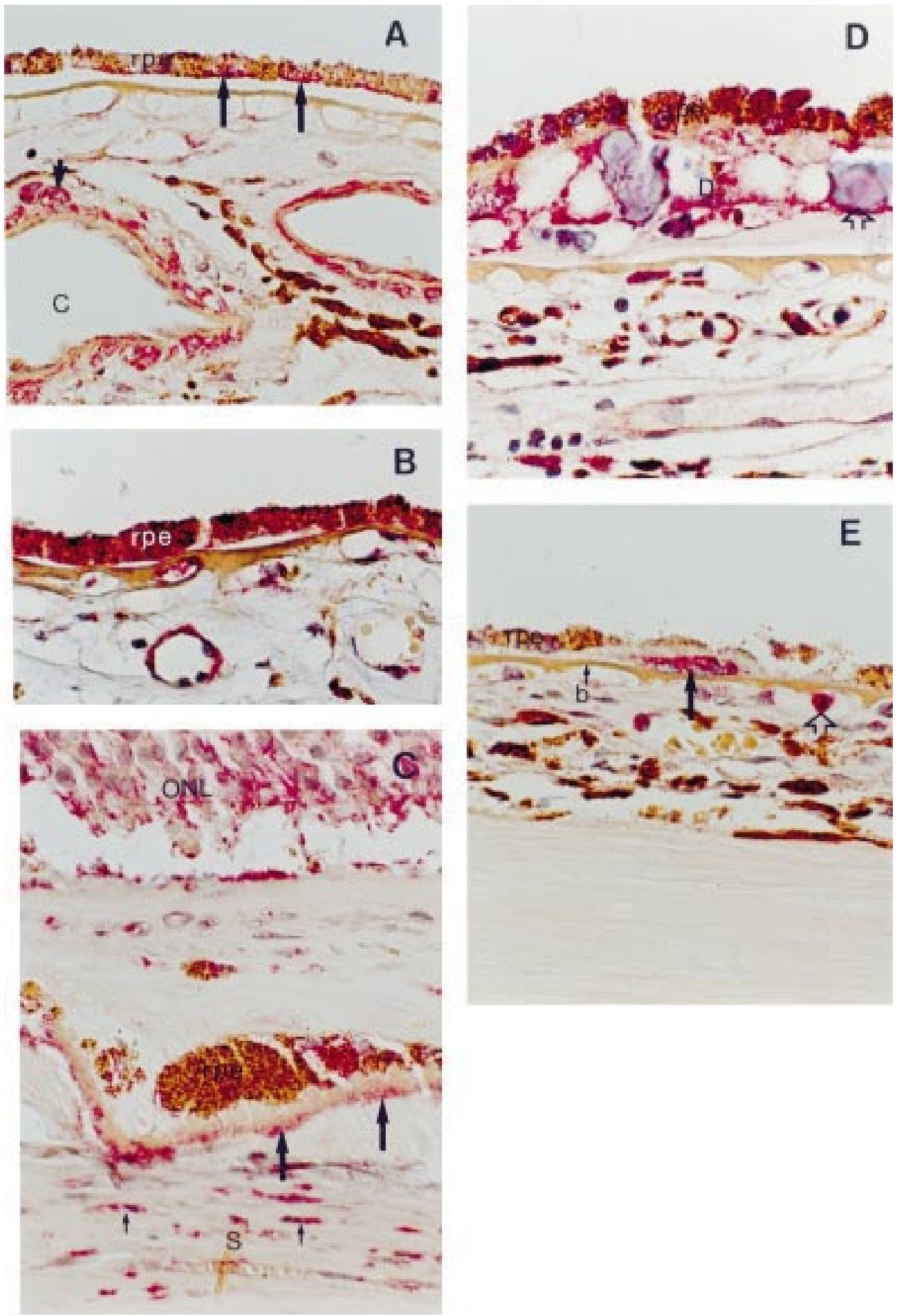

Figure 1 Light microscopic images of immunohistochemistry with anti-VEGF antibodies. (A) Typical example of VEGF expression in a control macula; VEGF is present in smooth muscle cells (short arrow) of choroidal blood vessels (C) and in some (long arrows) of the retinal pigment epithelial cells (rpe). (B) The expression of VEGF in the RPE is increased in ARM maculae in comparison with control maculae. (C) The outer nuclear layer (ONL) and basal laminar deposit (long arrows) show expression of VEGF in this macula with neovascular macular degeneration. The myofibroblast cells (small arrows) in the scar tissue (S) contain VEGF as well. (D) Expression of VEGF in a large drusen (D) with calcified bodies (open arrow) in an ARM macula. (E) Macrophages (long arrow) that have infiltrated Bruch's membrane (b) in a ARM macula show intense staining for VEGF. A monocyte (open arrow) shows VEGF expression as well. Original magnification $\times 400$

The blood vessels in the choroid also showed a significantly increased expression of VEGF in ARM maculae. No differences in RPE staining of ARM maculae compared with controls were found with anti-b-FGF, and anti-PDGF antibodies. About $50 \%$ of the human maculae with early ARM showed VEGF, TGF- $\beta$, and $\mathrm{b}-\mathrm{FGF}$ staining in BLD. Localisation of these angiogenic growth factors in the BLD, which deposit is correlated with the development of neovascular ARMD, points towards their involvement in the pathogenesis of subretinal 

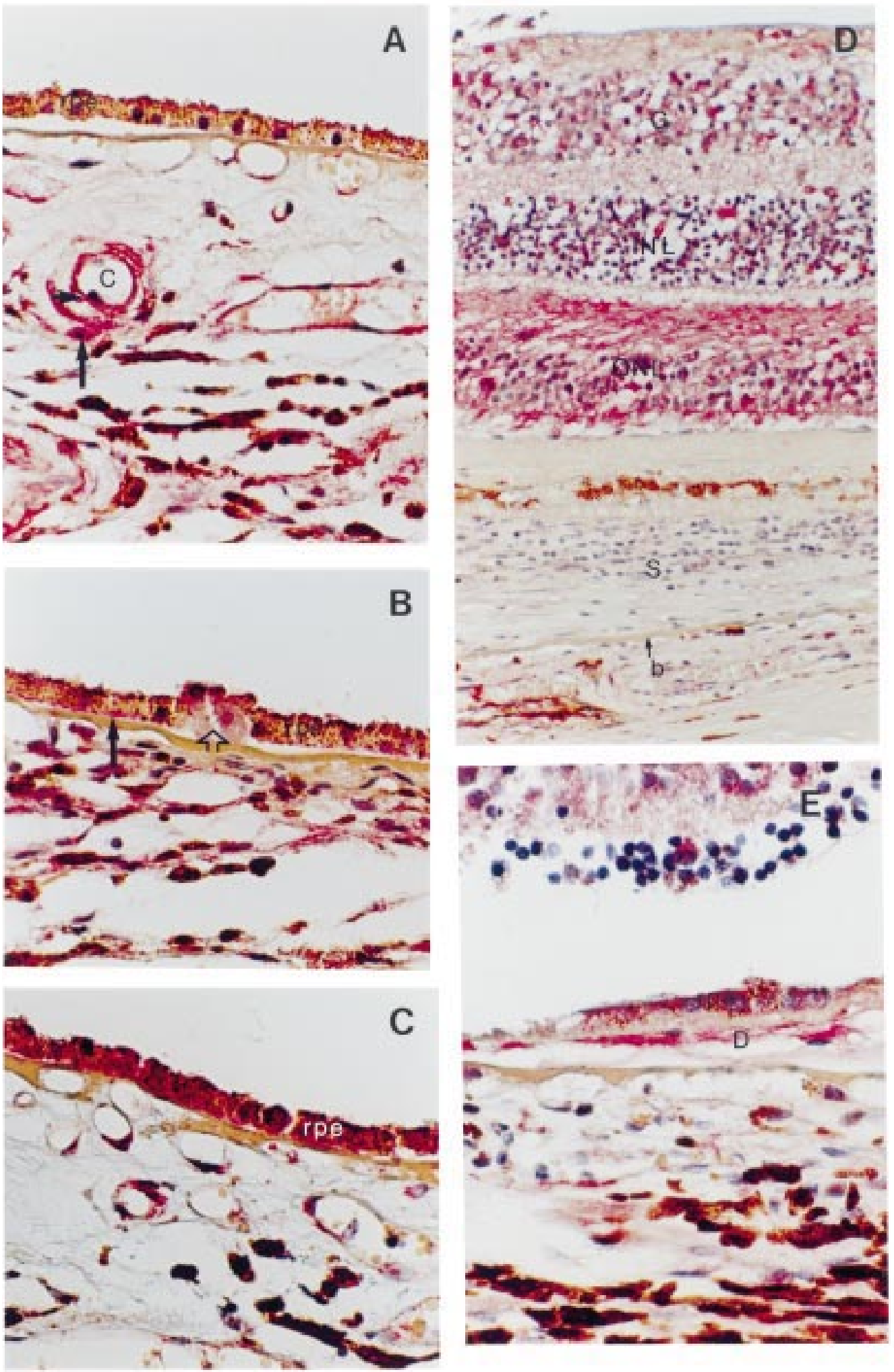

Figure 2 Light microscopic images of immunohistochemistry with anti-TGF- $\beta$ ( $A$ and $B), b-F G F(C)$, and PDGF-AA $(D$ and $E$ ) antibodies. (A) Control maculae show TGF- $\beta$ expression in smooth muscle cells (long arrow) and endothelial cells (short arrow) of choroidal blood vessels $(C)$. The RPE shows only faint staining in most of the control maculae. (B) $T G F-\beta$ expression is increased in the RPE of this typical ARM macula. Basal laminar deposit (long arrow) contains

$T G F-\beta$ as well. Note that the most prominent RPE staining is present on top of a drusen (open arrow) that itself shows no staining. (C) A typical example of an ARM macula that shows b-FGF expression in the RPE. (D) PDGF-AA expression in a macula with neovascular macular degeneration. The retina demonstrates PDGF-AA expression, whereas the retina in control maculae shows no staining at all. Note that the expression in the outer nuclear laver (ONL) is more prominent than in the inner nuclear layer (INL) and ganglion cell layer (G). (E) PDGF expression in a large drusen (D) in a macula with neovascular macular degeneration. $S=$ scar tissue, $b=$ Bruch's membrane. Original magnification $\times 400$. 

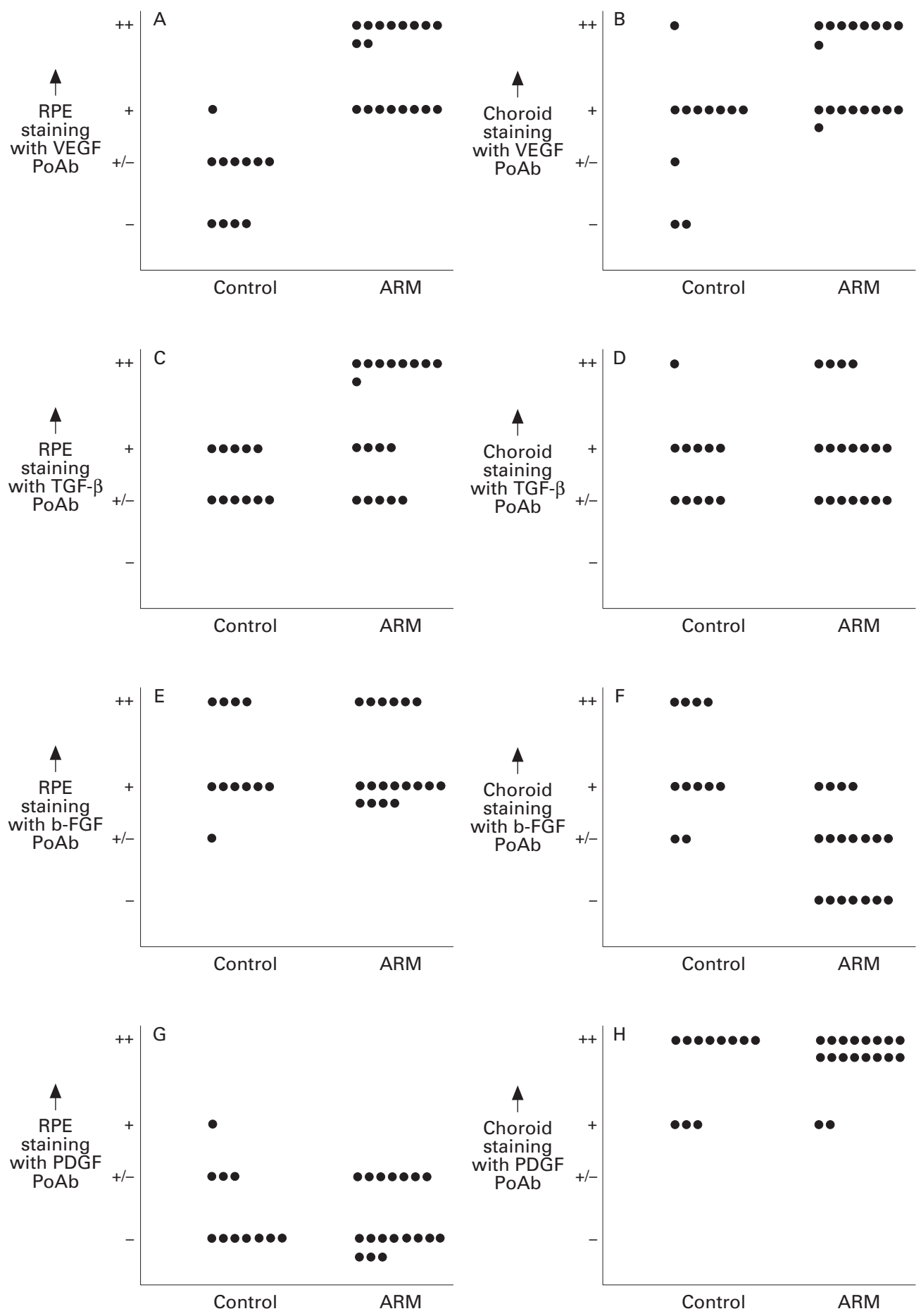

Figure 3 Comparison of the immunohistochemical expression of $V E G F$ ( $A$ and $B$ ), TGF- $\beta$ ( $C$ and $D$ ), $b-F G F$ ( $E$ and $F)$, and PDGF-AA (G and $H)$ in $R P E(A, C, E, G)$ and choroid $(B, D, F, H)$ between control maculae and $A R M$ maculae. PoAb = Polyclonal antibody.

neovascularisation. Since the postmortem times of controls and ARM cases were the same (mean 7 hours; $t$ test, $\mathrm{p}=0.7$ ) the differences between controls and cases cannot be caused by differences in postmortem times.

Expression of VEGF in many cell types, in vivo as well as in vitro, is strongly induced by a number of factors including hypoxia and ischaemia. ${ }^{32-35}$ Recently, it has been shown that human RPE cells in culture synthesise and secrete $\mathrm{VEGF}^{20}$ and that VEGF RNA levels are increased under hypoxic circumstances. ${ }^{36}$
Atrophy of the choriocapillaris and atherosclerosis resulting in relative ischaemia of the outer retina are assumed to be involved in the development of neovascular ARMD. ${ }^{237-39}$ In our study we found higher levels of VEGF in the RPE and choroid, as well as in the outer nuclear layer of maculae with ARM. Furthermore, the inner nuclear layer of the retina showed faint staining as well. In contrast, Miller et al found an increase of VEGF expression in the inner nuclear layer, but not in the outer nuclear layer of ischaemic retina, in a 
primate model for retinal neovascularisation. ${ }^{33}$ This difference could be attributed to the two separate vascular beds supplying the retina with oxygen and nutrients. A retinal capillary network that supplies the inner nuclear layer, and ganglion cell layer, and a network of extraretinal capillaries in the choroid supplying the RPE and the outer nuclear layer. The former is involved in diabetic retinopathy, which has been studied by Miller et al. ${ }^{33}$ The latter is involved in neovascular ARMD. ${ }^{12}$ These results indicate that the differentially increased VEGF staining in the outer and inner retinal layers in neovascular ARMD and in proliferative diabetic retinopathy, respectively, could be due to ischaemia caused by insufficiency of either of the capillary beds. Furthermore, recent findings of Pe'er et al support the contention of differential expression of VEGF in the retina as they demonstrated spatial localisation of VEGF mRNA in retinae of several other ischaemic retinal disorders. ${ }^{40}$ Other studies reported no VEGF staining in the RPE cells of normal young individuals/ animals. $^{21330}$ The weak staining of the RPE cells in our (older) control specimens could therefore be the result of an age-related increase in VEGF levels. Consequently, a small age-related component of the increased VEGF immunoreactivity in RPE cells from ARM cases can not be excluded.

As can be seen from Figure 3 more than half of the eyes with ARM show markedly increased VEGF staining (++) in the retinal pigment epithelium. None of the control eyes showed such staining. It is known that the evolution of early ARM to neovascular macular degeneration shows a lot of variation and the causal relation between the subsequent stages of ARM has not been established. In fact, it is known that not all eyes with early ARM progress to neovascular ARMD. However, it could well be that it is just a matter of time for neovascularisation to develop. On the other hand one could think of other factors (angiogenesis inhibitors) that are known to be produced by the retina that slow down this process. ${ }^{41}$ Therefore, we think it is valid to speculate that the increased expression of VEGF in ARM maculae could be one factor in a multifactorial development of neovascular macular degeneration.

In the present study, we demonstrated an intense expression of VEGF in infiltrating macrophages in ARM. The infiltration of macrophages through Bruch's membrane has been assumed to be involved in the process of neovascularisation in ARM. ${ }^{42-44}$ This migration could well be promoted by the increased levels of VEGF in maculae with ARM. ${ }^{45}$

TGF- $\beta$ is an indirect angiogenic growth factor that stimulates angiogenesis by inducing the production of other angiogenic factors like VEGF. ${ }^{46}$ TGF- $\beta$ plays an important role in the formation of extracellular matrix. ${ }^{10}$ It increases the production of matrix molecules and inhibits matrix degradation through stimulation of protease inhibitor synthesis, and inhibiting the synthesis of proteases. ${ }^{10}$ We demonstrated a significantly increased expression of TGF- $\beta$ in the RPE cells of maculae with early stages of ARM, strongly suggesting that TGF- $\beta$ could be involved in the accumulation of extracellular deposits such as BLD and drusen. BLD contains many extracellular matrix molecules such as collagen type IV, laminin, glycosaminoglycans, and several other carbohydrate structures. ${ }^{47-49}$ Furthermore, TGF- $\beta$ is highly chemotactic to monocytes. ${ }^{50}$ The increased expression of this growth factor in the RPE cells of early ARM maculae could contribute to the infiltration of macrophages through Bruch's membrane.

Basic FGF has been reported to be able to rescue photoreceptors from degeneration..$^{52}$ Although we have demonstrated b-FGF expression in the RPE, we could not demonstrate higher levels of this growth factor in the RPE cells of maculae with early stages of ARM or with neovascular ARMD (and subsequent degeneration of photoreceptors) compared with control specimens. Therefore, we can confirm the results of two recent papers, demonstrating expression of b-FGF in RPE cells involved in surgically removed neovascular membranes, ${ }^{11}{ }^{13}$ but we cannot point to a pathogenic role of b-FGF in the early stages of ARM. Furthermore, we have found a significantly decreased expression of b-FGF in the choroidal blood vessels in maculae with early stages of ARM compared with control maculae, indicating that b-FGF may not be contributing to early stages of ARM where other potent angiogenic factors like VEGF act as endothelial cell mitogen.

We demonstrated an increased expression of PDGF in the outer nuclear layer of three out of 17 maculae with early ARM, and in all maculae with neovascular ARMD, whereas none of the control maculae showed expression of PDGF in this layer. However, not all specimens contained all retinal layers, so it seemed unwise to perform statistical analysis on the staining characteristics of the retinal layers in this study. Similar to the results of Reddy et al, we did not see expression of PDGF in the RPE cells. ${ }^{13}$ Since PDGF is highly growth promoting and chemotactic to the RPE cells, ${ }^{14}$ the increased expression of PDGF in the outer nuclear layer could be attributed to its participation in the migration of RPE cells towards the inner retina, often seen during ARMD.

In conclusion, we have demonstrated that increased staining of a number of angiogenic growth factors can be observed in the early stages of ARM. Therefore, they may be involved in the early pathogenesis of neovascular ARMD. The increased levels of VEGF in RPE cells, and the outer nuclear layer of maculae with ARM might be caused by a relative hypoxia of the outer retina. Increased TGF- $\beta$ expression in the RPE cells of maculae with early stages of ARM could, in addition to its indirect angiogenic role (for example, stimulating the production of angiogenic growth factors like VEGF), induce the accumulation of extracellular deposits such as BLD and drusen. It is imperative to emphasise here that a specific inhibition of VEGF can prevent neovascularisation in a mouse model of ischaemia induced 
retinal neovascularisation. ${ }^{53}$ Therefore, it might be speculated that the identification of changes in VEGF levels in human maculae with ARM can provide us with a molecular target for antiangiogenic therapies in treating neovascular ARMD. ${ }^{54}$

The human tissues used in this study are tissues, or parts thereof, donated for transplantation purposes, which could not be used for implantation in a patient. We thank the donor and his family for their generosity and we thank the BIS foundation his family for their generosity and we thank the BIS foundation
(Leiden, Netherlands) and the cornea bank of the Netherlands Ophthalmic Research Institute (Amsterdam, Netherlands) for Ophthalmic Research Institute (Amsterdam
their assistance in obtaining the material.

1 Green WR, Enger C. Age-related macular degeneration histopathologic studies. The 1992 Lorenz E Zimmerman Lecture. Ophthalmology 1993;100:1519-35.

2 Kliffen M, van der Schaft TL, Mooy CM, de Jong PTVM Morphologic changes in age-related maculopathy. Microsc Res Tech 1996; (in press).

3 Bird AC, Bressler NM, Bressler SB, Chisholm IH, Coscas $\mathrm{G}$, Davis MD, et al. An international classification and grading system for age-related maculopathy and agerelated macular degeneration. Surv Ophthalmol 1995;39: related 74 .

4 Vingerling JR, Dielemans I, Hofman A, Grobbee DE, Hijmering M, Kramer CF, et al. Prevalence of age-related maculopathy in the Rotterdam study. Ophthalmology 1995 ; 102:205-10.

5 Klein R, Klein BEK, Linton KLP. Prevalence of age-related maculopathy. The Beaver Dam Eye Study. Ophthalmology 1992;99:933-43.

6 Sarks JP, Sarks SH, Killingsworth MC. Evolution of geographic atrophy of the retinal pigment epithelium. Eye 1988;2:552-77.

7 Bressler NM, Bressler SB, Fine SL. Age-related macular degeneration. Surv Ophthalmol 1988;32:375-413.

8 Folkman J, Shing Y. Angiogenesis. [Review] f Biol Chem 1992;267:10931-4.

9 Ferrara N, Heinsohn H, Walder CE, Bunting S, Thomas GR. The regulation of blood vessel growth by vascular endothelial growth factor. [Review] Ann NY Acad Sci 1995;752:246-56.

10 Sporn MB, Roberts AB, Wakefield LM, de Crombrugghe B. Some recent advances in the chemistry and biology of transforming growth factor-beta. [Review] $\mathcal{F}$ Cell Biol 1987 105:1039-45.

11 Amin R, Puklin JE, Frank RN. Growth factor localization in choroidal neovascular membranes of age-related macular degeneration. Invest Ophthalmol Vis Sci 1994;35:3178-88.

12 Sivalingam A, Kenney J, Brown GC, Benson WE, Donoso L. Basic fibroblast growth factor levels in the vitreous of patients with proliferative diabetic retinopathy. Arch Ophthalmol 1990;108:869-72.

13 Reddy MR, Zamora RL, Kaplan HJ. Distribution of growth factors in subfoveal neovascular membranes in age-related macular degeneration and presumed ocular histoplasmosis sysndrome. Am f Ophthalmol 1995;120:291-301.

14 Yoshida $M$, Tanihara $\mathrm{H}$, Yoshimura N. Platelet-derived growth factor gene expression in cultured human retinal prowth factor gent epithelial cells. Biochem Biophys Res Commun 1992;189:66-71.

15 Leschey KH, Hackett SF, Singer JH, Campochiaro PA. Growth factor responsiveness of human retinal pigmen epithelial cells. Invest Ophthalmol Vis Sci 1990;31:839-46.

16 Tanihara $\mathrm{H}$, Yoshida $\mathrm{M}$, Matsumoto $\mathrm{M}$, Yoshimura $\mathrm{N}$. Identification of transforming growth factor-beta expressed in cultured human retinal pigment epithelial cells. Invest Ophthalmol Vis Sci 1993;34:413-9.

17 Ocrant I, Fay CT, Parmelee JT. Expression of insulin and insulin-like growth factor receptors and binding proteins by retinal pigment epithelium. Exp Eye Res 1991;52:581-9.

18 Ishigooka H, Aotaki-Keen AE, Hjelmeland LM. Subcellular localization of bFGF in human retinal pigment epithelium in vitro. Exp Eye Res 1992;55:203-14.

19 Campochiaro PA, Sugg R, Grotendorst G, Hjelmeland LM. Retinal pigment epithelial cells produce PDGF-like
proteins and secrete them into their media. Exp Eye Res proteins and secrete.

20 Adamis AP, Shima DT, Yeo KT, Yeo TK, Brown LF, Berse $\mathrm{B}$, et al. Synthesis and secretion of vascular permeability factor/vascular endothelial growth factor by human retina pigment epithelial cells. Biochem Biophys Res Commun 1993;193:631-8.

21 Lopez P, Sippy B, Lambert H, Thach A, Hinton D. Transdifferentiated retinal pigment epithelial cells are immunoreactive for vascular endothelial growth factor in surgically excised age-related macular degeneration related choroidal neovascular membranes. Invest Ophthalmol Vis Sci 1996;37:855-68.

22 Bird AC. Bruch's membrane change with age. Br F Ophthalmol 1992;76:166-8.

23 Pauleikhoff D, Barondes MJ, Minassian D, Chisholm IH, Bird AC. Drusen as risk factors in age-related macular disease. Am f Ophthalmol 1990;109: 8-43.

24 Green WR, McDonnell PJ, Yeo JH. Pathologic features of senile macular degeneration. Ophthalmology 1985;92:61527.
25 Sarks SH. Ageing and degeneration in the macular region: a clinico-pathological study. Br F Ophthalmol 1976;60:32441 .

26 Sheraidah G, Steinmetz R, Maguire J, Pauleikhoff D, Marshall J, Bird AC. Correlation between lipids extracted from Bruch's membrane and age. Ophthalmology 1993;100:4751.

27 van der Schaft TL, de Bruijn WC, Mooy CM, Ketelaars DA, de Jong PTVM. Element analysis of the early stages of age-related 10

28 van der Schaft TL, de Bruijn WC, Mooy CM, Oron FG, Mulder PG, de Jong PTVM. Histologic features of the early stages of age-related macular degeneration. A statistical analysis. Ophthalmology 1992;99:278-86.

29 Vinores SA, Kuchle M, Mahlow J, Chiu C, Green WR, Campochiaro PA. Blood-ocular barrier breakdown in eyes with ocular melanoma. A potential role for vascular endothelial growth factor/vascular permeability factor. $\mathrm{Am}$ f Pathol 1995;147:1289-97.

30 Brogi E, Winkles JA, Underwood R, Clinton SK, Alberts GF, Libby P. Distinct patterns of expression of fibroblast growth factors and their receptors in human atheroma and nonatherosclerotic arteries. Association of acidic FGF with plaque microvessels and macrophages. 7 Clin Invest 1993;92:2408-18.

31 Gray K, Eitzman B, Raszmann K, Steed T, Geboff A, McLachlan $\mathrm{J}$, et al. Coordinate regulation by diethyltilbestrol of the platelet-derived growth factor-A (PDGF-A) and -B chains and the PDGF receptor alphaand beta-subunits in the mouse uterus and vagina: potential mediators of estrogen action. Endocrinology 1995; 136:325-40.

32 Minchenko A, Bauer T, Salceda S, Caro J. Hypoxic stimulation of vascular endothelial growth factor expression in vitro and in vivo. Lab Invest 1994;71:374-9.

33 Miller JW, Adamis AP, Shima DT, D'Amore PA, Moulton RS, O'Reilly MS, et al. Vascular endothelial growth factor/ vascular permeability factor is temporally and spatially correlated with ocular angiogenesis in a primate model. $A m \mathcal{F}$ Pathol 1994;145:574-84.

34 Shweiki D, Itin A, Soffer D, Keshet E. Vascular endothelial growth factor induced by hypoxia may mediate hypoxiainitiated angiogenesis. Nature 1992;359:843-5.

35 Sharma HS, Schaper W. The role of growth factors during development of a collateral circulation in the porcine heart. In: Cummins P, ed. Growth factors and the cardiovascular system. Amsterdam: Kluwer Academic Publishers, 1993

36 Aiello LP, Northrup JM, Keyt BA, Takagi H, Iwamoto MA. Hypoxic regulation of vascular endothelial growth factor in retinal cells. Arch Ophthalmol 1995;113:1538-44.

37 Vingerling JR, Dielemans I, Bots ML, Hofman A, Grobbee DE, de Jong PT. Age-related macular degeneration is associated with atherosclerosis. The Rotterdam study. Am $\mathcal{F}$ Epidemiol 1995;142:404-9.

38 Kliffen M, de Jong PTVM, Luider TM. Protein analysis of human maculae in relation to age-related maculopathy. $L a b$ Invest 1995;73:267-72

39 Ramrattan RS, van der Schaft TL, Mooy CM, de Bruyn CM, Mulder PGH, de Jong PTVM. Morphometric analysis of Bruch's membrane, the choriocapillaris and the choroid in aging. Invest Ophthalmol Vis Sci 1994;35:2857-64.

40 Pe'er J, Shweiki D, Itin A, Hemo I, Gnessin H, Keshet E. Hypoxia-induced expression of vascular endothelial growth factor by retinal cells is a common factor in neovascularizing ocular diseases. [See comments] Lab Invest 1995;72: 638-45.

41 Glaser BM, Campochiaro PA, Davis JLJ, Sato M. Retinal pigment epithelial cells release an inhibitor of neovascularipigment epithelial cells release an inhibitor

42 Penfold PL, Killingsworth MC, Sarks SH. Senile macular degeneration: the involvement of immunocompetent cells. Graefes Arch Clin Exp Ophthalmol 1985;223:69-76.

43 Lopez PF, Grossniklaus HE, Lambert HM, Aaberg TM, Capone A Jr, Stemberg P Jr, et al. Pathologic features of surgically excised subretinal neovascular membranes in age-related macular degeneration. Am $\mathcal{f}$ Ophthalmol 1991;112:647-56.

44 Killingsworth MC, Sarks JP, Sarks SH. Macrophages related to Bruch's membrane in age-related macular degeneration. Eye 1990;4:613-21.

45 Clauss M, Gerlach M, Gerlach H, Brett J, Wang F, Familletti PC, et al. Vascular permeability factor: a tumorderived polypeptide that induces endothelial cell and monocyte procoagulant activity, and promotes monocyte monocyte procoagulant activity, and promo
migration. $\mathcal{F}$ Exp Med 1990;172:1535-45.

46 Pertovaara L, Kaipainen A, Mustonen T, Orpana A, Ferrara $\mathrm{N}$, Saksela $\mathrm{O}$, et al. Vascular endothelial growth factor is induced in response to transforming growth factor-beta in fibroblastic and epithelial cells. F Biol Chem 1994;269: 6271-4.

47 van der Schaft TL, Mooy CM, de Bruijn WC, Bosman FT, de Jong PTVM. Immunohistochemical light and electron microscopy of basal laminar deposit. Graefes Arch Clin Exp Ophthalmol 1994;232:40-6.

48 Kliffen M, Mooy CM, Luider TM, de Jong PTVM. Analysis of carbohydrate structures in basal laminar deposit in aging human maculae. Invest Ophthalmol Vis Sci 1994;35: 2901-5.

49 Kliffen M, Mooy CM, Luider TM, Huijmans JGM, Kerkvliet S, de Jong PTVM. Identification of glycosaminoglycans in age-related macular deposits. Arch Ophthalmol 1996;114:1009-14. 
50 Wahl SM, Hunt DA, Wakefield LM, McCartney-Francis N, Wahl LM, Roberts AB, et al. Transforming growth factor type beta induces monocyte chemotaxis and growth factor

51 LaVail MM, Unoki K, Yasumura D, Matthes MT, Yancopoulos GD, Steinberg RH. Multiple growth factors, cytokines, and neurotrophins rescue photoreceptors from the damaging effects of constant light. Proc Natl Acad Sci USA 1992;89:11249-53.

52 Faktorovich EG, Steinberg RH, Yasumura D, Matthes MT, LaVail MM. Basic fibroblast growth factor and local injury protect photoreceptors from light damage in the rat. $7 \mathrm{Neu}$ rosci 1992;12:3554-67.

53 Aiello LP, Pierce EA, Foley ED, Takagi H, Chen H, Riddle $\mathrm{L}$, et al. Suppression of retinal neovascularization in vivo by inhibition of vascular endothelial growth factor (VEGF) using soluble VEGF-receptor chimeric proteins. Proc Natl Acad Sci USA 1995;92:10457-61.

54 D'Amato RJ, Adamis AP. Angiogenesis inhibition in age-related macular degeneration. [Guest editorial] $O p h$ thalmology 1995;102:1261-2. 